\title{
A New Operation for the Cure of Vaginal Cystocele.*
}

\author{
By Ernest W. Hex Groves, M.D., B.S. (Lond.), \\ Assistant Surgeon to the Bristol General Hospital.
}

Or the many conditions of prolapse and displacement of the genital canal, that which affects the anterior vaginal wall and involves the posterior wall of the bladder is the one which hitherto has been least amenable to operative treatment. Vaginal cystocele exists under two conditions, viz., that in which it only forms part of a uterine descent bulging out with the anterior vaginal wall, and that in which it forms a distinct hernia or pouch, pushing down the vagina before it but leaving the uterus in a normal position. For both these conditions several operations have been devised, such as Sim's V-shaped elytrorrhaphy, the ordinary elliptical anterior colporrhaphy, and Stoltz's operation, where a circular piece of the anterior vaginal wall is removed and the gap closed by a purse-string suture. All these methods are essentially the same, and consist in removing a greater or less extent of the anterior vaginal wall, and bringing the margins of the gap together, so that the support left for the remedy of the prolapse is a scar of the vagina together with the general narrowing of the vaginal outlet. But $I$ think it is recognised that the remote results of such operations are disappointing. And if we regard the cystocele as a hernia, whose radical cure we have to undertake, it is not surprising that methods which depend for their success upon the fixation of so distensible and movable a structure as the vaginal wall should lead to failure. For it is evident that any cause which has sufficiently distorted a normal vagina to produce a cystocele, is capable of distorting a restored vagina to reproduce the hernia.

But the true floor of the pelvis is formed by the levatores ani muscles, and through the gap between them the urethra and vagina emerge. Any prolapse of the vagina and of the bladder can only result when this gap has been widened either by the gradual pressure from above from a heavy or retroverted uterus, or by injury received during parturition. It would therefore seem more natural, in seeking to remedy these conditions, to deal primarily with the more fixed structures of the pelvic floor than merely to deal with the movable organs which protrude through it. And I think it is probable that whatever measure of success does follow such operations as anterior colporrhaphy, depends chiefly on the indirect narrowing of the outlet through the pelvic floor. In the radical cure

- Read at a meeting of the Obstetrical Society of London, Feb. 1st, 1805. 
of an ordinary abdominal hernia, after dealing with the peritoneal sac, the most important procedure-and that on which the success of the operation depends, is the closure of the muscular gap through which the hernia has protruded; and where the situation of the hernial orifice admits of this being done efficiently (as in the case of an oblique inguinal hernia) the result is correspondingly good, whereas

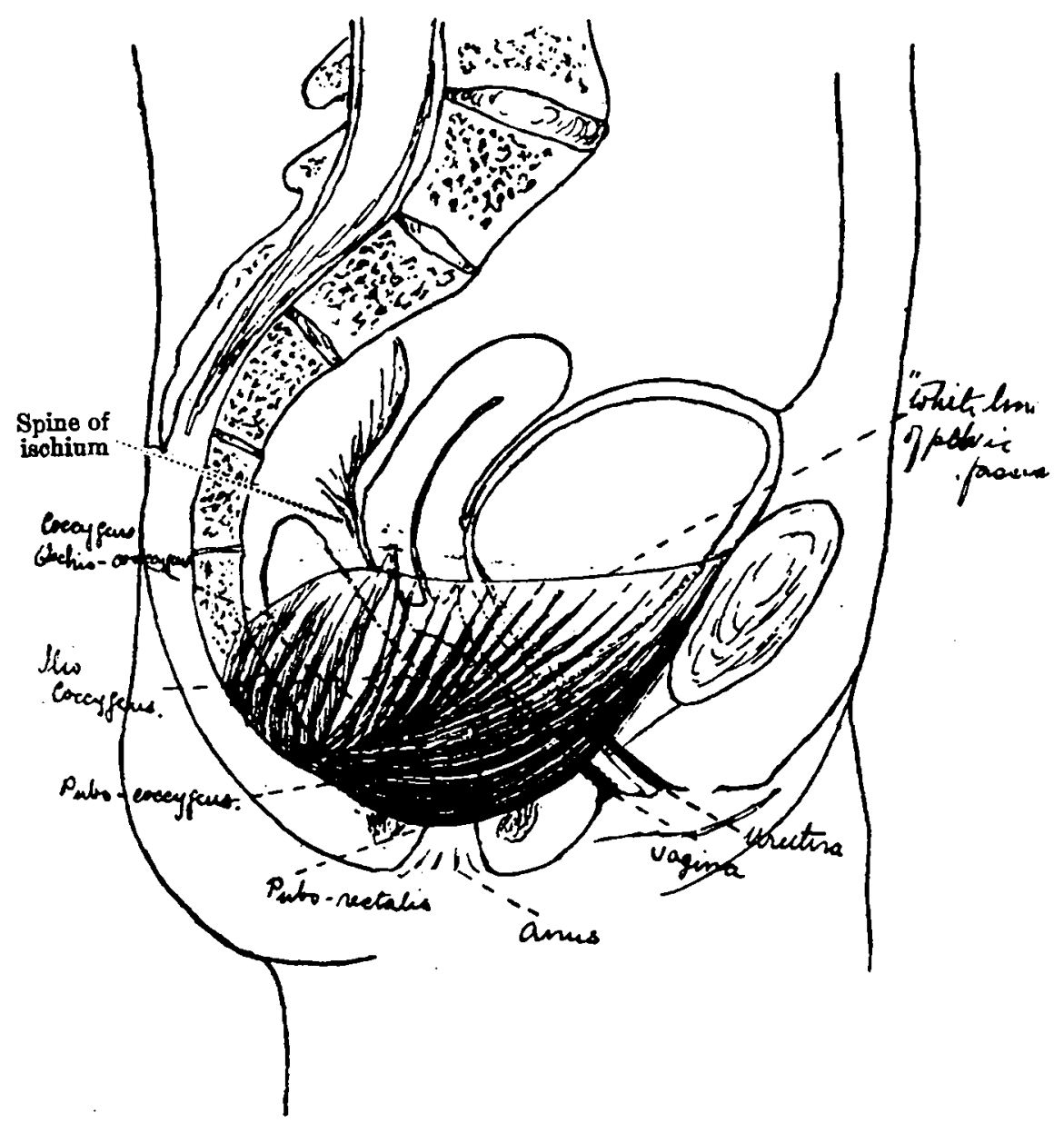

Fig. 1.

when it is difficult to reconstruct a firm muscular plane (as in the case of a femoral, direct inguinal or umbilical hernia) the result is too often failure.

Now, in the case of hernia of the bladder, there is ready to hand a most efficient plane formed by the levatores ani muscles, which bound the hernial orifice of the neck of the sac on either side.

The levator ani muscle is usually described as arising from the 
pubes, the "white line" of the pelvic fascia and the spine of the ischium, and as inserted into the perineum, rectum and ano-coccygeal raphe. And it is represented as a muscle whose direction is primarily vertical. But it is more correct to consider that the main origin is from the pubes, and the main insertion into the coccyx, its direction being horizontal, and its fibres forming a sling for the rectum and ragina.

Morphologically it represents the flexor caudæ muscle of tailed vertebrates, and may be divided into four parts-the pubo-rectalis, from the pubes to the perineum; the pubo-coccygeus, from the pubes to the anus and ano-coccygeal raphe; the ilio-coccygeus and ilio-

Distance of the edge of one levator ani from that of the other.

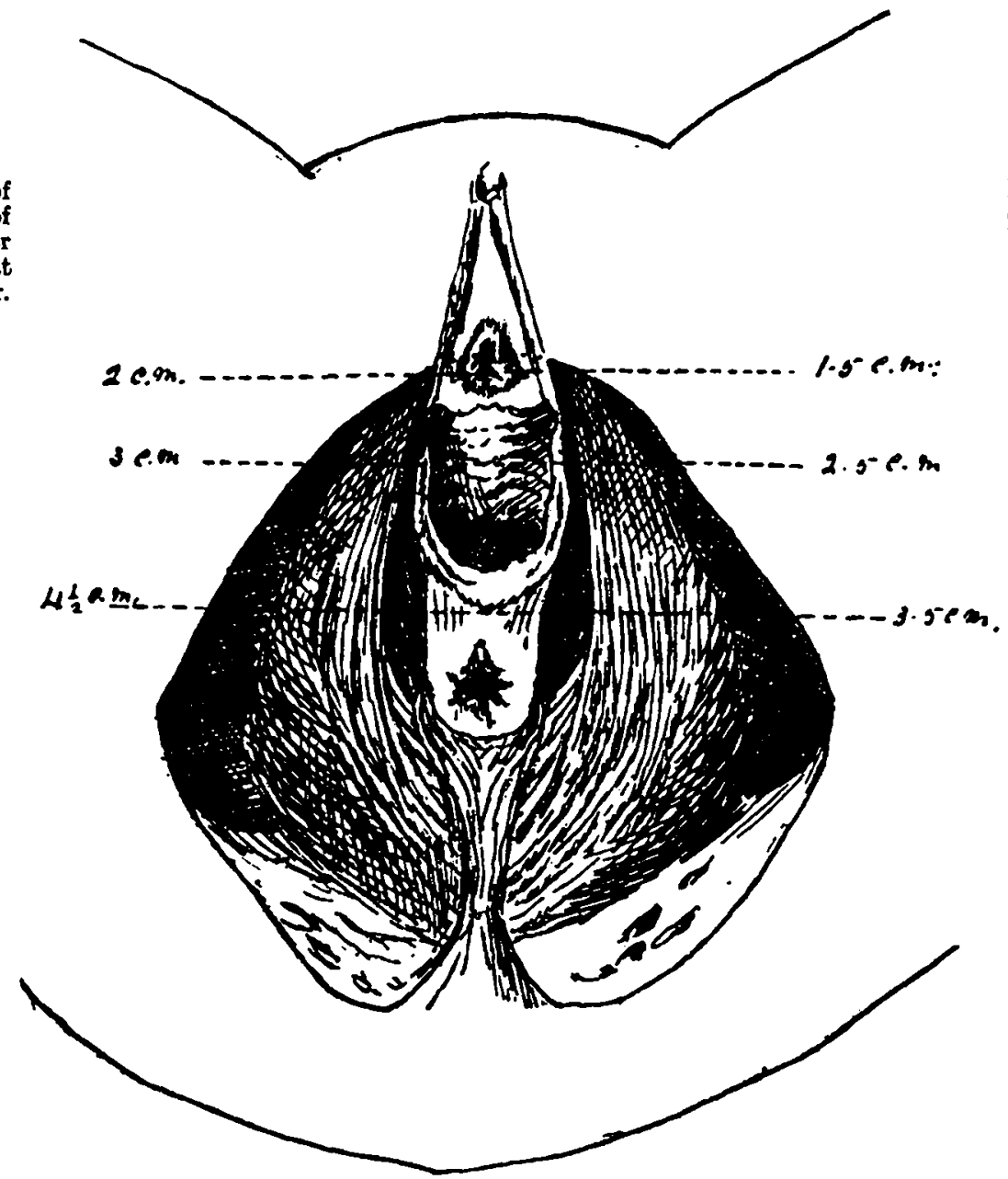

Fig. II
Depth of the edge of the levator ani from the skin surface.

NotE. - By the term edge of unuscle is meant the edge of the thick muscular band, the thin fibres which meet in the perineal body being ignored. 
sacralis, from the white line and ischial spine to the coccys and sides of the sacrum.* The iliac origin of the last two portions has disappeared. Fig. 1 shows the disposition of these several parts in relation to the pelvic viscera, and it shows well the horizontal disposition of the main fibres.

Regarded from below, after the superficial perineal muscles and the triangular ligament with the overlying structures have been removed (Fig. 2) the two muscles are seen to form the pelvic floor, in the centre of which lies a median slit through which the urethra

\section{Urethre.}

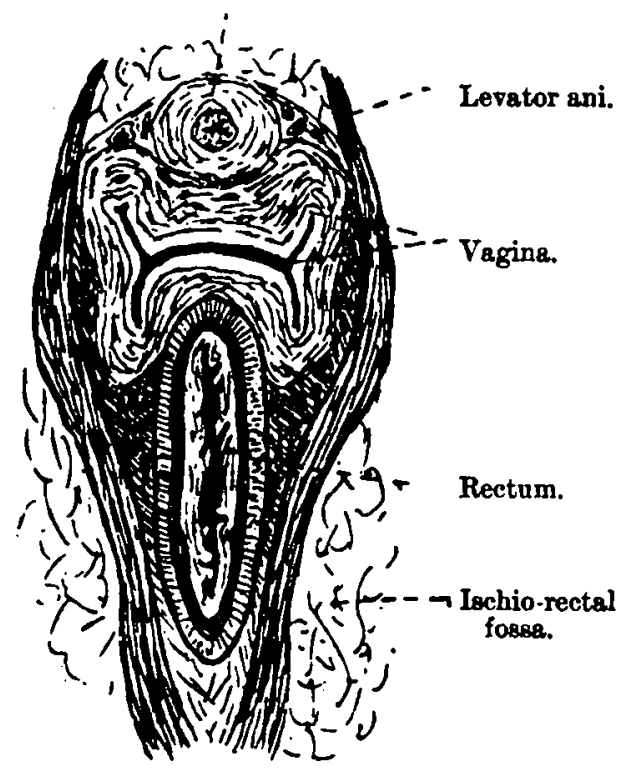

Fig. III.

\section{Horizontal section through the Urethre, Vagines and rectun a phort distance above their terminations.}

(after Henle).

and vagina emerge. At their origin from the pubic bones the two muscles are $2 \mathrm{c} . \mathrm{m}$. apart, at the centre of the vaginal outlet $3 \mathrm{c} . \mathrm{m}$., at the central point of the perineum $4 \frac{1}{2}$ c.m.; this latter figure referring to the main bundle of the pubo-rectalis muscle and not to the thin median fibres which actually meet one another in the perineum. At these three points the lower border of the main muscle lies $1.5 \mathrm{c} . \mathrm{m} ., 25 \mathrm{c.m}$., and $3.5 \mathrm{c.m}$. below the surface of the perineal structures.

Fig. 3 shows a horizontal section of the urethra, vagina, and

* "Cunningham's Text-book of Anatomy," p. 111. 


\section{Groves: Vaginal Cystocele}

rectum a short distance above their termination, and it is seen how these structures are embraced by the horizontally-disposed tibres of the levatores ani. The lower border of the muscle can easily be felt, and in a relaxed raginal outlet demonstrated by the fingers (Fig. 4).

The various stepe of the operation I am about to describe will now, I think, be quite clear (see Fig. 5). A transverse incision is

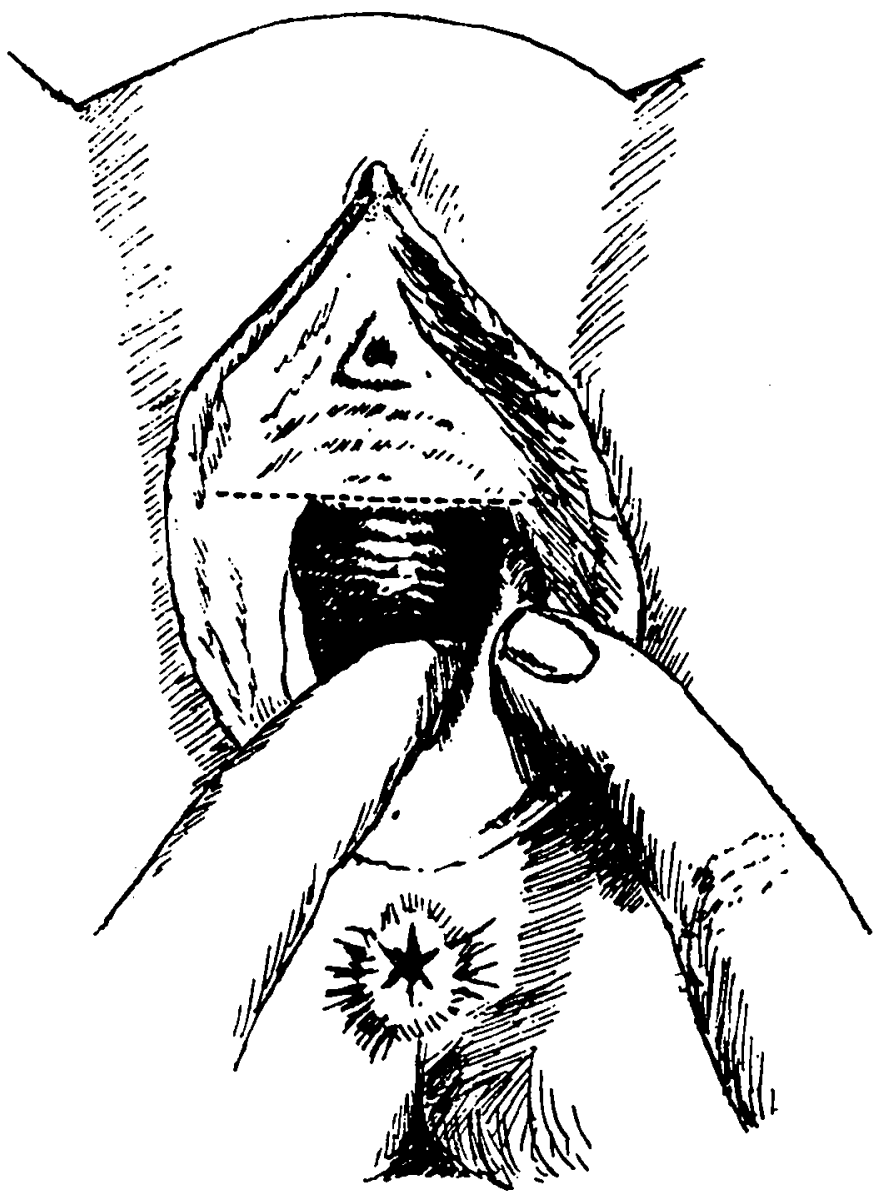

Fig. IV.

Demonstration of edge of the lerator ani through vaginal wall (after Howard Kelly).

The dotted line shews the position of the incision.

made from one labium majus to the other about $3 \mathrm{c} . \mathrm{m}$. behind the urethral orifice. The incision divides the whole thickness of the vagins. The two margins of this incision are then retracted upwards and downwards, and with the finger or handle of a scalpel the urethra 
and bladder in front are separated from the vagina behind. The margins of the levatores ani muscles are then sought for and defined in either angle of the wound. It will be found that they can easily be brought into apposition with little or no tension. Two or three mattress sutures are then passed right through both muscles as far

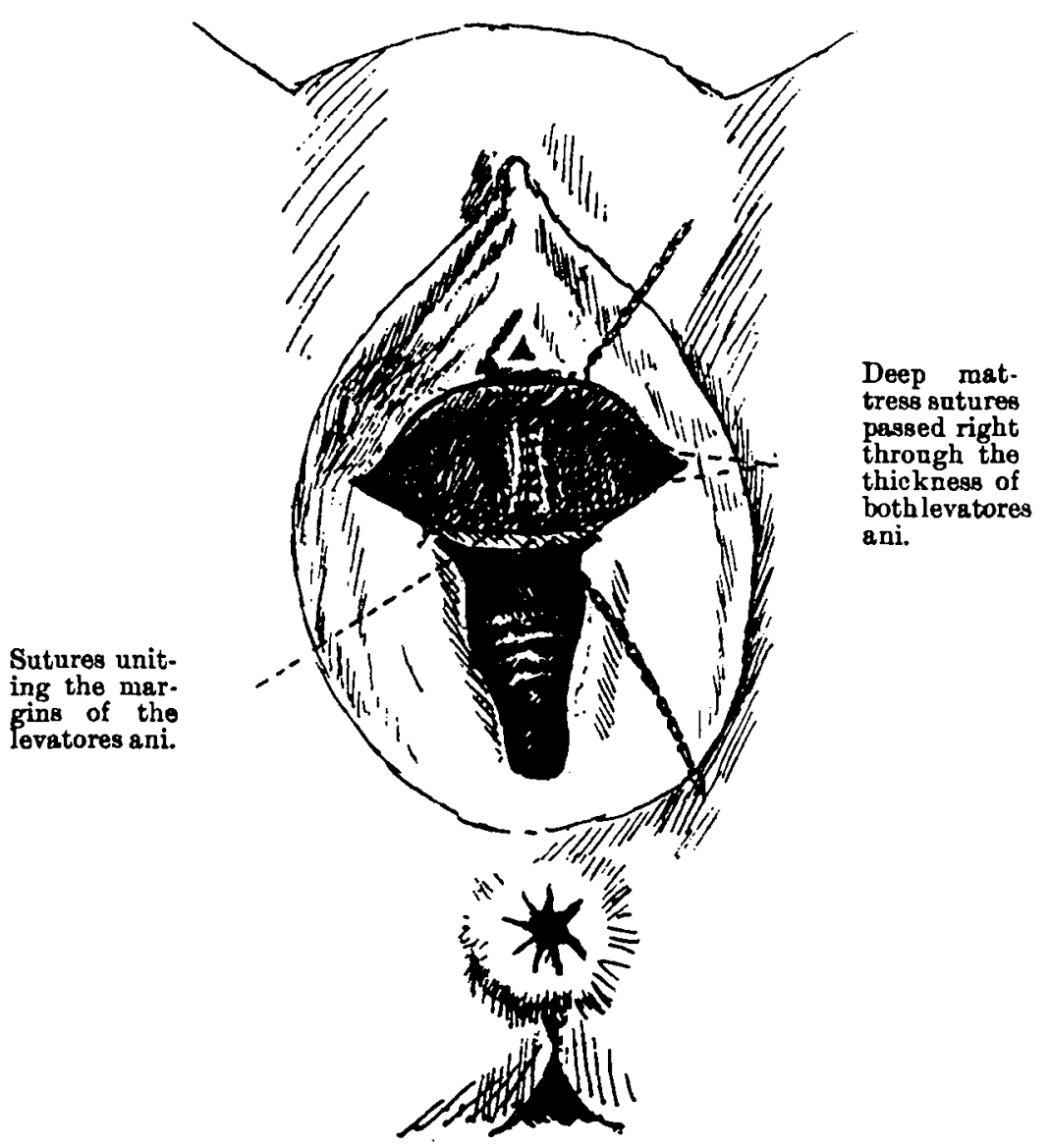

Fig. V.

The edges of the transverse incision throngh the vagins are held back by hooks. Note the narrowing of the vaginal outlet cansed by the
euturing of the levatores ani.

from their margin as can be done without undue tension and tied on the outer surface of one or other. These will lie about 1.5 c.m. from the margins of the muscle, which are then united by fine interrupted sutures. This forms a median muscular mass about $2 \mathrm{o.m}$. long and $1.5 \mathrm{c} . \mathrm{m}$. thick, lying beneath and supporting the base of the bladder. The margins of the original incision are now 
united by catgut after any redundant vaginal mucous membrane has been removed. The cicatrix lies in a very superficial position, where a little gauze packing (which is changed every time the catheter is passed) serves to keep the wound clean.

The first case in which I performed this operation was nearly two years ago. The displacement has not recurred, and, moreover, the woman has recently boen delivered of a full-term living child, and the pelvic floor is still quite sound. 